Review Article

\title{
Liver Fibrosis and Mechanisms of the Protective Action of Medicinal Plants Targeting Inflammation and the Immune Response
}

\author{
Florent Duval, ${ }^{1}$ Jorge E. Moreno-Cuevas, ${ }^{1}$ María Teresa González-Garza, \\ Carmen Maldonado-Bernal, ${ }^{2}$ and Delia Elva Cruz-Vega ${ }^{1}$ \\ ${ }^{1}$ Catedra de Terapia Celular, Escuela de Medicina, Tecnológico de Monterrey, Avenida Morones Prieto 3000 Pte., \\ 64710 Monterrey, NL, Mexico \\ ${ }^{2}$ Laboratorio de Investigación en Inmunología y Proteómica, Hospital Infantil de México Federico Gómez, \\ Calle Dr. Márquez 162, 06720 Ciudad de México, DF, Mexico
}

Correspondence should be addressed to Delia Elva Cruz-Vega; cruzvegade@gmail.com

Received 12 September 2014; Accepted 29 November 2014

Academic Editor: David A. Hart

Copyright (C) 2015 Florent Duval et al. This is an open access article distributed under the Creative Commons Attribution License, which permits unrestricted use, distribution, and reproduction in any medium, provided the original work is properly cited.

\begin{abstract}
Inflammation is a central feature of liver fibrosis as suggested by its role in the activation of hepatic stellate cells leading to extracellular matrix deposition. During liver injury, inflammatory cells are recruited in the injurious site through chemokines attraction. Thus, inflammation could be a target to reduce liver fibrosis. The pandemic trend of obesity, combined with the high incidence of alcohol intake and viral hepatitis infections, highlights the urgent need to find accessible antifibrotic therapies. Medicinal plants are achieving popularity as antifibrotic agents, supported by their safety, cost-effectiveness, and versatility. The aim of this review is to describe the role of inflammation and the immune response in the pathogenesis of liver fibrosis and detail the mechanisms of inhibition of both events by medicinal plants in order to reduce liver fibrosis.
\end{abstract}

\section{Introduction}

Fibrosis is an inappropriate tissue repair of the liver resulting from almost all of the chronic liver injuries including alcohol induced damage, chronic viral hepatitis (HBV and HCV), autoimmune, parasitic, and metabolic diseases, and less frequently toxic or drugs exposure [1]. When fibrosis is not controlled, it can further progress into cirrhosis. In contrast with the traditional idea that cirrhosis is an irreversible state, there is solid evidence indicating that fibrosis even cirrhosis could be reversible [2].

Liver fibrosis is an important public health concern with significant morbidity and mortality [3]. Hundreds of millions of people worldwide suffer from cirrhosis [4]. Chronic viral hepatitis B and C, alcoholic liver diseases, and nonalcoholic fatty liver diseases are the three most common causes [5]. Prevalence of chronic liver diseases, hence hepatic fibrosiscirrhosis, is predicted to increase, due in part to the rising prevalence of obesity and metabolic syndrome, especially in developed countries [6].

Pathogenesis of liver fibrosis is complex and varies between different kinds of hepatic injuries. Usually after acute liver damage, parenchymal cells regenerate and replace the necrotic and apoptotic cells; this process is associated with an inflammatory response and a limited deposition of extracellular matrix. When injury persists, eventually the regenerative response fails and hepatocytes are substituted by abundant extracellular matrix mainly composed by collagen type I-III-IV, fibronectin, elastin, laminin, and proteoglycans. Activated hepatic stellate cells (HSCs) are the main sources of extracellular matrix [7].

Inflammation is an important and complex feature of liver fibrosis. Following liver injury, an accumulation of recruited inflammatory cells in the injurious site occurs. Cells from innate immune response, including, platelets, neutrophils, macrophages, mast cells, and natural killer (NK) cells, and 
from the adaptive immune response, such as T- and B-cells, participate in the fibrogenesis process. A wide repertoire of pro- and anti-inflammatory compounds, which encompasses cytokines, chemokines, growth factors, and products of oxidative stress, mediates the inflammatory response of immune cells during the fibrosis process [8]. HSCs also take part actively in the inflammation process through interaction with diverse types of immune cells [9]. Furthermore, HSCs conversion from a quiescent to an activated state characterized by a myofibroblast-like phenotype responsible for proliferation and excessive extracellular matrix deposition is regulated by inflammatory mediators, including transforming growth factor-beta (TGF- $\beta$ ) and tumor necrosis factor-alpha $(\mathrm{TNF}-\alpha)[7]$.

There is no standard treatment for liver fibrosis, although it is known that reducing liver injury events, such as interruption of alcohol intake or successful treatment of viral hepatitis, contributes to control of the process. Nevertheless, these actions do not seem to be sufficient in the vast majority of patients to avoid progression to cirrhosis [8]. Even though important advances have been made in the knowledge of the pathogenesis of hepatic fibrosis for the past 20 years, there are still important gaps to translate this basic information into efficient antifibrotic drugs. Treatment strategies for liver fibrosis should take into account the versatility of its pathogenesis and acting on all the events involved starting with inflammation.

Supported by their safety, cost-effectiveness, and versatility, medicinal plants enjoy a growing popularity as antifibrotic agents. We already reviewed how medicinal plants reduce liver fibrosis by inhibiting HSCs activation and reducing ECM deposition [10]. However, other antifibrotic mechanisms could explain this activity such as suppression of inflammation and the immune response. This review focuses on another way bioactive compounds from thirteen known hepatoprotective plants, including Curcuma longa, Silybum marianum, Ginkgo biloba, Salvia miltiorrhiza, Glycyrrhiza glabra, Scutellaria baicalensis, Bupleurum falcatum, Phyllanthus species, Berberis aristata, Picrorrhiza kurroa, Ginseng species, Andrographis paniculata, and coffee species, reduce liver fibrosis: the suppression of inflammation and the immune response.

\section{Role of Inflammation and Immune Response in the Pathogenesis of Liver Fibrosis}

2.1. Platelets. Platelets are among the first cells recruited to the injurious site. Platelets initiate coagulation cascade to limit blood loss converting fibrinogen into fibrin [8]. Involvement of platelets in the fibrogenesis results from its capacity to release cytokines like TGF- $\beta$ and platelet derived growth factor (PDGF) [11]. Platelets also produce serotonin, which mediates liver regeneration [12]. Additionally, platelets release the platelet derived chemokine $(\mathrm{C}-\mathrm{X}-\mathrm{C})$ ligand 4 (CXCL4), also known as platelet factor 4 (PF4) [13]. Patients with advanced hepatitis $\mathrm{C}$ virus-induced fibrosis or nonalcoholic steatohepatitis, as well as animal models of liver fibrosis induced by carbon tetrachloride $\left(\mathrm{CCl}_{4}\right)$ and thioacetamide (TAA), have increased intrahepatic levels of CXCL4 suggesting a role of CXCL4 in the fibrogenic process. This role were further exposed by observing that CXCL4(-/-) mice have reduced liver damage and changes in the expression of fibrosis-related genes, including matrix metalloproteinase (MMP)-9, tissue inhibitor of metalloproteinases (TIMP)-1, TGF- $\beta 1$, and interleukin (IL)-10, as well as a decreased infiltration of neutrophils and CD8+ T cells into the liver. In the same study, CXCL4 stimulated the proliferation, chemotaxis, and chemokine expression of HSCs in vitro [14].

2.2. Neutrophils. During liver injury, neutrophils rapidly infiltrate and transmigrate into the hepatic parenchyma. Transmigration is a chemokine-mediated event that involves adhesion molecules such as integrin and intracellular adhesion molecule-1 (ICAM-1). Next, neutrophils adhere to hepatocytes through hepatocyte ICAM-1 and $\beta 2$ integrins and neutrophil Mac-1 (CD11b/CD18). Contact between hepatocytes and neutrophils triggers formation of reactive oxygen by nicotinamide adenine dinucleotide phosphate (NADPH) oxidase and release of proinflammatory proteases through degranulation leading to killing of hepatocytes, one of the fibrogenic stimuli [15]. Besides, neutrophils synthesize human neutrophil peptide-1 (HNP-1) and IL-17A, which enhance hepatic fibrosis by inducing cell proliferation [16] and activating HSCs [17], respectively. Implication of neutrophils in inflammation also involves reactive oxygen formation [18]. However, importance of neutrophils in the fibrogenic process has not always been clear. Indeed, bile duct-ligated rats depleted of neutrophils showed no difference in hepatic fibrogenesis compared with control rats [19]. Neutrophils have been also associated with liver repair since neutrophils depletion blocks early collagen degradation in repairing cholestatic rat livers [20].

2.3. Mast Cells. Mast cells are immune cells involved in immunoglobulin E- (IgE-) associated immediate hypersensitivity and allergic disorders and in various liver diseases. They are naturally present in the liver [21, 22]. These cells could play a role in the development of liver fibrosis as suggested by the correlation between the increased number of mast cells and the amount of liver fibrosis in chronic liver diseases such as primary biliary cirrhosis and alcoholic liver diseases [22]. Nevertheless, this idea is controversial. Studies based on mast cell-deficient mutant Ws/Ws rats and mice did not find any important role for mast cells in the development of liver fibrosis [23, 24]. However, mast cells elaborate a wide range of mediators that have been associated with different activities in liver fibrosis, including tryptase, chymase proteases, interleukins (IL-3, IL-4, IL-5, IL-6, IL-9, IL-10, IL-11, IL-12, IL-13, IL-15, IL-16, IL-18, IL-25, and TNF- $\alpha$ ), chemokines (macrophage inflammatory protein- $1 \alpha$ (MIP$1 \alpha)$ ), hematopoietic factors (granulocyte macrophage colony stimulating factor (GM-CSF)), stem cell factor (SCF), TGF- $\beta$, vascular endothelial growth factor (VEGF), nerve growth factor (NGF), several MMPs, heparin, histamine, chondroitin sulfates, cathepsin, carboxypeptidases, and peroxidase [21]. 
The chymase has been linked with the production of angiotensin II and the development of myocardium and renal fibrosis [21] while mast cell tryptase induces proliferation, migration, and synthesis of collagen type I by fibroblasts $[25,26]$.

2.4. Natural Killer. NK cells are involved in defending host against pathogens like hepatitis $C$ virus by recruiting virusspecific $\mathrm{T}$ cells and inducing antiviral immunity in liver [9]. Liver has a rich population of NK cells. Upon liver injury, NK cells accumulate through chemokine receptor CXCR6 dependent pathway exacerbating the inflammatory response and promoting hepatic fibrogenesis [27]. The influence of NK cells, especially the CD1d-restricted natural killer T (NKT) cells, on the fibrogenic response has been observed by using mice lacking mature NKT cells caused by genetic disruption of the CD1d molecule. CD1d-knockout mice developed minimal hepatic fibrosis induced by administration of TAA, which was accompanied by reduction in collagen type I alpha 1 (COL1A1) and TIMP-1 expression [28]. Other molecules have been identified as contributors of the profibrogenic effect of NK cells. Mice fed a methionine-choline-deficient (MCD) diet, an animal model of nonalcoholic fatty liver disease, and depleted in NKT cells have significantly attenuated hedgehog and osteopontin expression and fibrosis suggesting that NKT cells promote fibrogenesis via osteopontin and hedgehog pathways [29]. Profibrogenic activity of NK cells also comes from its ability to produce proinflammatory cytokines such as IL-4 and IL-13 [30]. Additionally, NK cells kill hepatocytes through release of tumor necrosis factor-related apoptosis-inducing ligand (TRAIL) and/or granzyme B leading to liver injury that could further progress in liver fibrosis. Nevertheless, NK and NKT cells have also drawn attention to inhibiting liver fibrosis [31]. NK cells and NKT reduce liver fibrosis by producing interferon gamma (IFN- $\gamma$ ) and inducing death of early or senescence of activated HSCs $[32,33]$. NK cells kill activated HSCs via retinoic acid early inducible 1/NKG2D dependent, TRAIL dependent, and Fas ligand dependent mechanisms, thereby ameliorating liver fibrosis $[34,35]$. The pattern of increased levels of NK cellactivating ligands (ribonucleic acid export 1 (RAE-1) in mice, MHC class I polypeptide-related sequence A (MICA) in human) and TRAIL receptors is not observed in quiescent and fully activated HSCs, making them resistant to such killing [31, 32]. Antifibrotic effect of NK cells can also be explained by the production of IFN $-\gamma$, which is a cytokine that directly inhibits HSCs activation leading to reduced liver fibrosis [36]. Additionally, IFN- $\gamma$ induces HSCs apoptosis in a signal transducer and activator of transcription 1 (STAT1) dependent manner, which inhibits HSCs proliferation, attenuates TGF- $\beta$ signaling, and stimulates NK cell cytotoxicity towards HSCs, or upregulating NKG2D and TRAIL expression on NK cells $[34,37]$.

2.5. Macrophages. Macrophages are central orchestrators of hepatic fibrogenesis [38] as proposed by the inhibition of the activation of HSCs in rat with suppressed macrophages infiltration [39] and the consequent reduction in fibrosis and inflammation in animal model of liver fibrosis depleted in macrophages [40, 41]. Upon liver injury, monocytes/macrophages are recruited. The recruitment process is mediated by chemokines and its receptors, especially $\mathrm{C}-\mathrm{C}$ motif chemokine receptor 8 (CCR8) and 2 (CCR2) and CC chemokine ligand 2 (CCL2, also named monocyte chemotactic protein-1 (MCP-1)) [41-43]. Macrophages regulate inflammation and fibrosis by producing factors such as TGF- $\beta$, IL-1 $\beta$, IL-8, PDGF, TNF- $\alpha$, and MCP-1 [38]. These factors have proven to promote activation, proliferation, chemotaxis, extracellular matrix accumulation, and survival of myofibroblasts $[44,45]$. Recently, macrophages have been described as mediators of the induction of liver fibrosis by activation of IkappaB kinase (IKK)/NF- $\kappa \mathrm{B}$ [46]. Inversely to their fibrogenic role in ongoing liver injury, macrophages have also a pivotal importance in liver repair [38, 47] since macrophages depletion during recovery leads to failure or retard of matrix degradation [40, 41]. Beneficial effects of macrophages during regeneration could be mediated by MMPs as well as others factors. Animals depleted with macrophages have sustained TIMPs messenger RNA expressions levels and reduced expression of MMP-2 and -13 [41]. Additionally, in a study where bone marrow-derived macrophages were delivered to animal model of advanced liver fibrosis, the macrophage therapy resulted in recruitment of host effectors cells, like endogenous macrophages and neutrophils, release of MMP-13 and -9, upregulation of anti-inflammatory IL-10, and reduction in hepatic myofibroblasts [48]. Macrophages can also favor liver fibrosis resolution by promoting HSCs apoptosis through TRAIL and MMP-9 production [49, 50]. These opposite effects of macrophages suggest that two distinct macrophage phenotypes mediate fibrogenesis and resolution [38,47]. GR-1+ subset of hepatic macrophages could be associated for the profibrogenic effects [51].

2.6. Lymphocytes. Following liver injury, inflammatory lymphocytes infiltrate the hepatic parenchyma [52] as evidenced by the increase in the number of all liver lymphocytes subsequent to induction of fibrosis by $\mathrm{CCl}_{4}$ in mice. Lymphocytes take part in the development of liver fibrosis, especially CD8+ T cells [53]. Transgenic anti-inflammatory IL-10 from hepatocytes attenuates fibrosis through reduction of CD8+ $\mathrm{T}$ cells [54]. Once lymphocytes infiltrated the liver, they attach directly to activated HSCs to modulate fibrogenic response and induce lymphocytes proliferation. This interaction occurs because HSCs act as antigen-presenting cells by upregulating membrane proteins human leukocyte antigen II (HLA-II) and CD40 during fibrogenesis as well as major histocompatibility complex (MHC) class II and CD11c [53, 55]. A further in vitro study of intercellular interaction showed that CD8+ and CD4+ T-lymphocytes from peripheral blood lymphocytes of $\mathrm{HBV} / \mathrm{HCV}$-infected patients with advanced fibrosis can be engulfed by HSCs, a process that involves ICAM-1 and integrin molecules as well as Racl and Cdc42 pathways, resulting in HSCs activation and consequent fibrogenesis [56]. Additionally, CD4+ T cells can induce fibrogenesis by secreting cytokines, including TNF- $\alpha$ and IL-2 [57]. Interestingly, $\mathrm{T}$ helper subsets seem to play divergent role in 
fibrogenesis since C57BL/6 mice, displaying a Th1 lymphocytes response, have minimal fibrosis compared with BALB/c mice which exhibit Th2 response [58]. Th1 subset produces high level of antifibrotic IFN- $\gamma$ whereas Th2 T cells produce high levels of profibrogenic cytokines mainly IL-4, IL-5, and IL-13 [59]. B lymphocytes are also involved in fibrogenesis; nevertheless its influence has been less investigated than $T$ cells. Evidence of the profibrotic effect of B cells is that B cell-deficient mice have markedly reduced fibrosis than wildtype mice following $\mathrm{CCl}_{4}$ administration [60]. B cells can also induce fibrosis by producing profibrotic cytokine IL-6 [61].

2.7. Hepatic Stellate Cells (HSCs). Almost all of the stimuli of inflammation converge to HSCs, which are not yet seen as a passive cell type in this process. Besides HSCs activation which is mediated by inflammatory species such as TGF- $\beta$ and TNF- $\alpha$, HSCs are involved in the recruitment of inflammatory cells through different mechanisms: by releasing chemokines and expressing cell adhesion molecules [62]. Chemokines are considered as the inflammatory mediators that modulate liver fibrosis by amplifying infiltration of inflammatory cells [63]. HSCs produce a wide range of profibrogenic and antifibrogenic chemokines and its receptors, including CCR2, CCR5, CCR7, CXCR3, CXCR4, CCL2 (MCP-1), CCL5 (also named regulated on activation, normal $\mathrm{T}$ cell expressed and secreted (RANTES)), CCL21, CXCL9, and CXCL10 (also named interferon gamma-inducible protein-10 (IP-10)) in schistosomiasis [64]. For example, CX3CL1/fractalkine soluble peptides produced by activated HSCs promote chemoattraction of monocytes and thus chronic inflammation of the liver, through CX3CR1 dependent signaling pathway [65]. Additionally, recruitment and migration of mononuclear cells within the perisinusoidal space of diseased livers might be the consequence of the interaction of HSCs with ICAM-1 and vascular cell adhesion protein-1 (V-CAM-1) ligand-bearing cells, such as lymphocyte function-associated antigen-1- or -Mac-1/very late activation antigen-4-positive inflammatory cells [66].

\section{Inflammation and Immune Response as Targets of Antifibrotic Medicinal Plants}

Since inflammation is a key process that contributes to the pathogenesis of liver fibrosis, to reduce inflammation and immune response is a relevant way to treat hepatic fibrosis $[67,68]$. All the reviewed plants produce compounds that suppress inflammation, thereby highlighting anti-inflammatory properties as an important antifibrotic mechanism of medicinal plants. Even though all the reviewed medicinal plants have been unequally investigated, they share common anti-inflammatory mechanisms.

Acute or chronic administration of almost all the hepatotoxic/fibrogenic agents triggers an inflammatory response in liver; thus bioactive compounds or extracts from medicinal plants have been tested in different model of hepatotoxicity and fibrosis, including $\mathrm{CCl}_{4}$, TAA, $\mathrm{MCD}$, high fat diet (HFD), ethanol, concanavalin A (ConA), dimethylnitrosamine $(\mathrm{DMN})$, bile duct ligation (BDL), lipopolysaccharide
(LPS), ischemia/reperfusion (I/R), and D-galactosamine (DGalN). To facilitate the comprehension, we divided anti-inflammatory mechanisms of medicinal plants observed in vivo in hepatotoxic models which use a single administration of the hepatotoxic agent to induce inflammation, generally LPS, D-GalN, ConA, $\mathrm{CCl}_{4}$, and I/R (Table 1), and those which used a subacute or chronic administration of the hepatotoxic agent such as fibrotic models, including $\mathrm{CCl}_{4}$, DMN, TAA, MCD, HFD, and BDL (Table 2).

3.1. Cytokines. All the reviewed medicinal plants reduce liver fibrosis by downregulating hepatic expression and secretion into bloodstream of inflammatory cytokines, which is illustrated by reduced protein and mRNA expression levels into liver and decreased serum levels of cytokines, respectively. Inflammatory cytokines targeted by vegetal compounds include TNF- $\alpha$, IL-1 $\alpha$, IL-1 $\beta$, IL-2, IL-4, IL-6, IL-12, IL-18, and IFN- $\gamma$. Suppression of liver inflammation also involves the upregulation of anti-inflammatory cytokine IL-10 hepatic level and inhibition of inducible nitric oxide synthase (iNOS) and cyclooxygenase-2 (COX-2) expression.

3.2. Chemokines. Besides cytokines, bioactive compounds from reviewed medicinal plants regulate chemokines expression to suppress liver inflammation. Recruitment of immune cells to the injury site is orchestrated by chemokines such as CXCL10, MCP-1, MIP-1, and high mobility group protein B1 (HMGB1) and by other molecules like ICAM-1. During liver injury, expression of chemokines and their receptors is upregulated [69]. HMGB1 is released actively by monocytes/macrophages or passively by necrotic cells [70]. In hepatocytes, HMGB1 release is mediated by nuclear translocation of interferon regulatory factor 1 (IRF-1) [71]. Following injury, HMGB1 translocates to the cytoplasm and into the extracellular space where it acts as both a cytokine and a chemokine promoting inflammation through Toll-like receptor (TLR)2/TLR4 pathways [72]. Hepatic expression, secretion, and/or cytoplasmic translocation of HMGB1, especially from hepatocytes, are inhibited by curcumin from C. longa, glycyrrhizin from G. glabra, and chlorogenic acid from coffee [73-77]. Moreover, chlorogenic acid suppresses IRF-1 nuclear translocation [76]. MCP-1 targets monocytes and T-lymphocytes [78]. MCP-1 expression is decreased by curcumin, caffeine, and magnesium lithospermate $\mathrm{B}$ from $S$. miltiorrhiza [79-84]. ICAM-1 and CXCL10 mediate adhesion and migration of T-lymphocytes in the liver [85]. ICAM-1 expression is suppressed by curcumin, silymarin, and ginsenoside Rg1 from $P$. ginseng [80, 86-88], while expression of CXCL10 is inhibited by curcumin, ginsenoside Rg1, and sodium tanshinone IIA sulfonate from S. miltiorrhiza [86, 87, 89]. Moreover, leukocytes attractant chemokines MIP-2, MIP- $1 \alpha$, and RANTES are inhibited by curcumin and sodium tanshinone IIA sulfonate $[79,89]$. Interestingly, MCP-1 and MIP-2, as well as TNF- $\alpha$, IL-12, COX-2, and iNOS, are also inhibited in vitro by curcumin in isolated rat Kupffer cells treated with LPS [79] and HSCs stimulated with PDGF [90] suggesting that curcumin could selectively target these cells to reduce inflammation. As a result of chemokines downregulation, medicinal plants block the recruitment of immune 


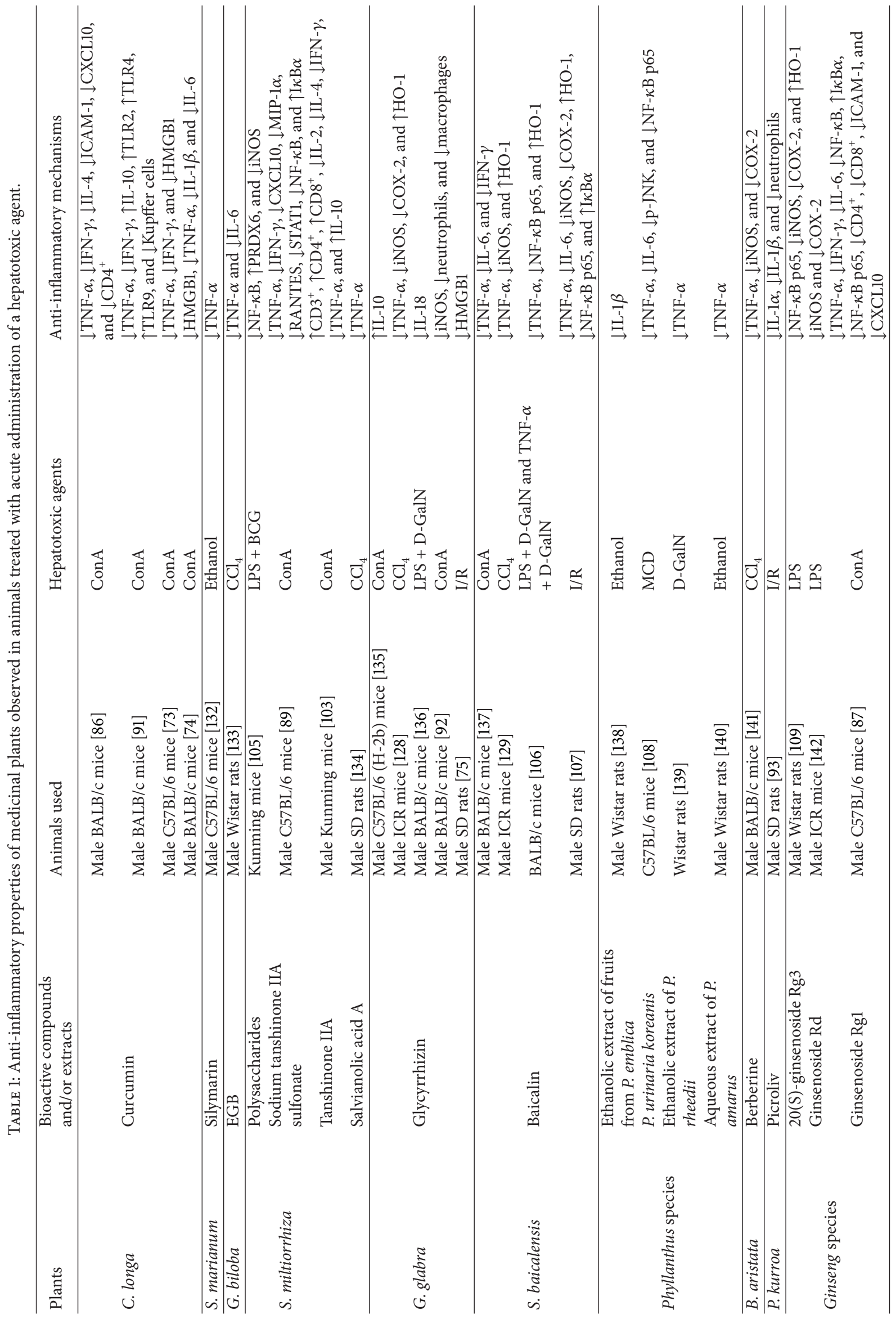




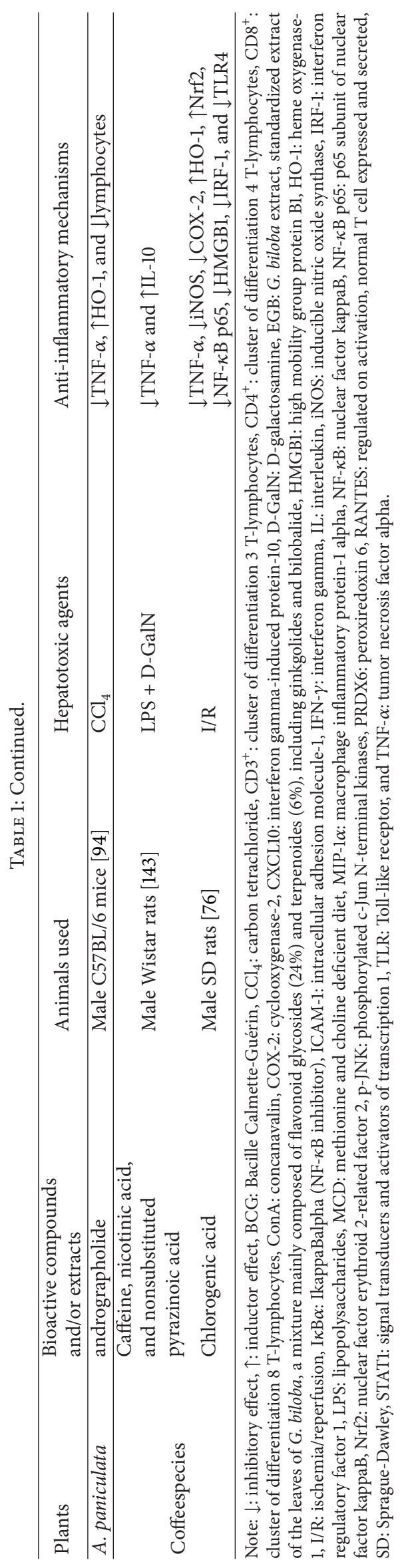




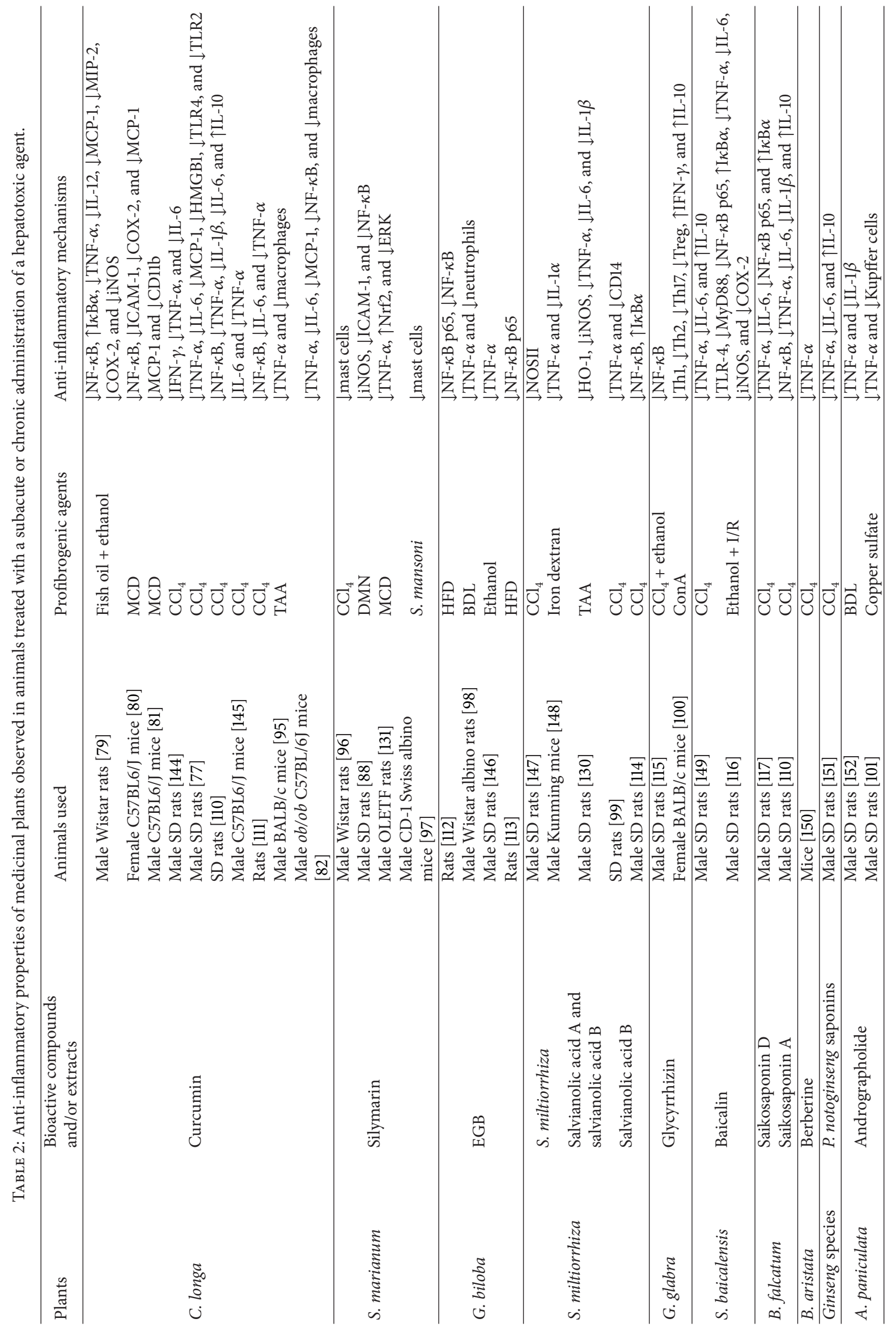




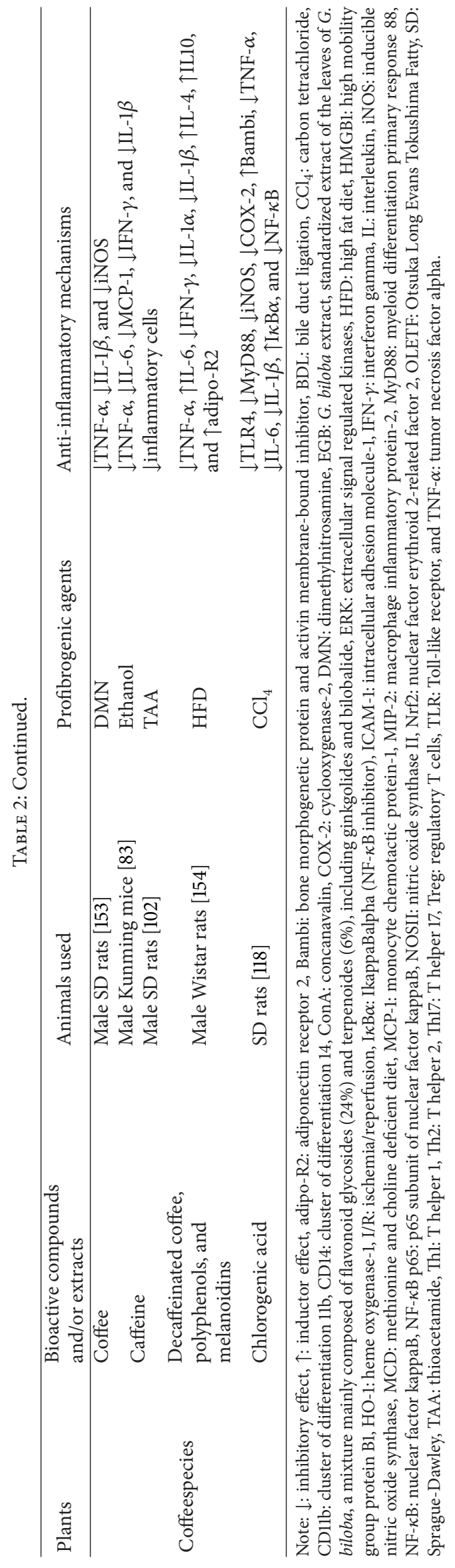


cells into the liver. Curcumin, silymarin, extract of G. biloba (EGB), salvianolic acid B from S. miltiorrhiza, glycyrrhizin, picroliv from $P$. kurroa, ginsenoside Rg1, andrographolide from A. paniculata, and caffeine block neutrophils, lymphocytes, Kupffer cells, and mast cells hepatic infiltration following liver injury $[81,82,86,87,91-102]$. However, tanshinone from $S$. miltiorrhiza increases T lymphocyte subset CD3+, $\mathrm{CD} 4+$, and CD8+ ratios in ConA treated mice [103].

3.3. Nuclear Factor-Kappa B $(N F-\kappa B)$. NF- $\kappa \mathrm{B}$ is a transcription factor implicated in the regulation of a wide range of genes related to apoptosis, inflammation, and immune response. Expression of many chemokines, cytokines, and other inflammatory mediators, including iNOS, COX-2, MIP-2, MCP-1, IL-12, and TNF- $\alpha$, is under control of NF$\kappa \mathrm{B}$ activation. Following liver injury, NF- $\kappa \mathrm{B}$ is activated. This occurs via IKK-mediated phosphorylation and consequent degradation of inhibitory molecules, such as IkappaBalpha $(\mathrm{I} \kappa \mathrm{B} \alpha)$ and phosphorylation of p65 subunit of NF- $\kappa \mathrm{B}$. The activated NF- $\kappa \mathrm{B}$ is then translocated into the nucleus where it binds to specific sequences of DNA to regulate gene expression of many inflammatory-related genes [104]. NF- $\kappa$ B activity is inhibited by curcumin, silymarin, EGB, salvianolic acid $\mathrm{B}$, polysaccharides, and sodium tanshinone IIA sulfonate from S. miltiorrhiza, glycyrrhizin, baicalin from S. baicalensis, saikosaponins A and D from B. falcatum, P. urinaria koreanis, 20(S)-ginsenoside Rg3, ginsenoside Rg1, and chlorogenic acid in different animal models $[76,79,80,82,87-89,105-$ 118]. This occurs via suppressing NF- $\kappa \mathrm{B}$ nuclear translocation, downregulating phosphorylation, or increasing cytosolic level expression of inhibitory protein $\mathrm{I} \kappa \mathrm{B} \alpha$ or inhibiting nuclear expression or phosphorylation of NF- $\kappa \mathrm{B}$ p65 subunit. Moreover, polysaccharides from $S$. miltiorrhiza inhibit NF- $\kappa \mathrm{B}$ through upregulation of peroxiredoxin 6 (PRDX6) expression [105]. Inhibition of NF- $\kappa$ B explains how medicinal plants reduce downstream induction of cytokines expression during liver fibrosis and suggests a common mechanism between their bioactive compounds. NF- $\kappa \mathrm{B}$ is regulated by the intracellular redox state; this implies that antioxidant compounds of reviewed medicinal plants reduce chronic liver injury-induced oxidative stress which is sensed by NF- $\kappa \mathrm{B}$ resulting in suppression of inflammation during liver fibrosis [119].

3.4. Toll-Like Receptors (TLRs). Toll-like receptors, especially TLR2 and TLR4, are central mediators of the inflammation during liver fibrosis. TLRs ligands include pathogenassociated molecular patterns (PAMPs) as well as dangerassociated molecular patterns (DAMPs) [120, 121]. DAMPs, such as HMGB1, are released as part of the fibrogenic cascade [122]. NF- $\kappa \mathrm{B}$ has been related to TLRs since stimulation of TLR2 leads to activation of NF- $\kappa \mathrm{B}$ through upregulation of myeloid differentiation primary response 88 (MyD88) [123]. In consequence, HMGB1-TLR2/TLR4-NF- $\kappa$ B signaling pathway appears as a potential therapeutic target to suppress inflammation in liver fibrosis. In $\mathrm{CCl}_{4}$-induced liver fibrosis animal model and ConA challenged mice, curcumin inhibits liver expressions of TLR2, TLR4, and TLR9 [77, 91]. Baicalin and chlorogenic acid suppress TLR4-mediated inflammatory signaling pathway by reducing hepatic level of TLR4 and MyD88 protein expression in I/R-treated animal model of alcoholic fatty liver disease [116] and $\mathrm{CCl}_{4}$-fibrotic rats $[76,118]$, respectively. In these studies, disruption of TLR4 pathway correlated with downregulation of iNOS, COX-2, TNF- $\alpha$, and IL- 6 hepatic expression as well as NF- $\kappa$ B inhibition $[76,116,118]$. Interestingly, chlorogenic acid also induces the liver expression of bone morphogenetic protein and activin membrane-bound inhibitor, the TGF- $\beta 1$ pseudoreceptor, by downregulating TLR4, providing a link between proinflammatory and profibrogenic signals [118].

3.5. Heme Oxygenase-1 (HO-1). Heme oxygenase-1 (HO-1) is a cytoprotective enzyme that is induced by a variety of stimuli, including cytokines, heavy metals, and oxidants [107]. HO1 is transcriptionally regulated by the binding of redoxsensitive transcription factors, such as activator protein-1 (AP-1) and nuclear factor erythroid 2-related factor 2 (Nrf2), to antioxidant redox elements located in the promoter of the ho-1 gene [124]. HO-1 exerts antioxidant, antiapoptotic, and anti-inflammatory functions following hepatic injuries [125]. The latter is mediated by inhibition of inflammatory response by targeting TNF- $\alpha$ and iNOS expression. Moreover, HO-1 induction reduces TLR4 overexpression and HMGB1 release $[126,127]$. Hence, HO-1 could play a significant role in mediating anti-inflammatory properties of medicinal plants in liver fibrosis. Salvianolic acids A and B, glycyrrhizin, baicalin, 20(S)-ginsenoside $\mathrm{Rg} 3$, andrographolide, and chlorogenic acid increase HO-1 expression, level, and/or activity [76, 94, $106,107,109,128-130]$. Additionally, chlorogenic acid and silymarin induce the nuclear translocation of Nrf2 facilitating its binding with ho-1 promoter $[76,131]$.

\section{Conclusion}

Medicinal plants could be a source of polyvalent antiliver fibrosis compounds targeting inflammation and the immune response. The importance of knowing the main mechanisms, by which medicinal plants act as antifibrotic agents, provides options for the development of pharmaceutical compounds and their subsequent use in medical practices. Since clinical studies are sparse and mainly use chronic hepatitis B and hepatitis $C$ patients to assess the hepatoprotective effects of medicinal plants, more clinical proofs of their anti-inflammatory properties on patients with fibrosis induced by other agents than HBV and HCV are urgently needed.

\section{Conflict of Interests}

The authors declare that there is no conflict of interests regarding the publication of this paper.

\section{Acknowledgments}

This work was partially funded by endowments from Tecnológico de Monterrey (cat-134) and the Zambrano-Hellion Foundation and supported by CONACYT for the PhD student grant. 


\section{References}

[1] E. Mormone, J. George, and N. Nieto, "Molecular pathogenesis of hepatic fibrosis and current therapeutic approaches," Chemico-Biological Interactions, vol. 193, no. 3, pp. 225-231, 2011.

[2] E. L. Ellis and D. A. Mann, "Clinical evidence for the regression of liver fibrosis," Journal of Hepatology, vol. 56, no. 5, pp. 11711180, 2012.

[3] V. Sánchez-Valle, N. C. Chávez-Tapia, M. Uribe, and N. Méndez-Sánchez, "Role of oxidative stress and molecular changes in liver fibrosis: a review," Current Medicinal Chemistry, vol. 19, no. 28, pp. 4850-4860, 2012.

[4] S. L. Friedman, "Liver fibrosis—from bench to bedside," Journal of Hepatology, vol. 38, pp. S38-S53, 2003.

[5] T. Poynard, P. Mathurin, C.-L. Lai et al., "A comparison of fibrosis progression in chronic liver diseases," Journal of Hepatology, vol. 38, no. 3, pp. 257-265, 2003.

[6] Y.-S. Lim and W. R. Kim, "The global impact of hepatic fibrosis and end-stage liver disease," Clinics in Liver Disease, vol. 12, no. 4, pp. 733-746, 2008.

[7] H. L. Reeves and S. L. Friedman, "Activation of hepatic stellate cells: a key issue in liver fibrosis," Frontiers in Bioscience, vol. 7, pp. d808-d826, 2002.

[8] N. C. Henderson and J. P. Iredale, "Liver fibrosis: cellular mechanisms of progression and resolution," Clinical Science, vol. 112, no. 5-6, pp. 265-280, 2007.

[9] H.-S. Yi and W.-I. Jeong, "Interaction of hepatic stellate cells with diverse types of immune cells: foe or friend?" Journal of Gastroenterology and Hepatology, vol. 28, no. 1, pp. 99-104, 2013.

[10] F. Duval, J. E. Moreno-Cuevas, M. T. González-Garza, C. Rodríguez-Montalvo, and D. E. Cruz-Vega, "Liver fibrosis and mechanisms of the protective action of medicinal plantstargeting hepatic stellate cell activation and extracellular matrix deposition," Chinese Medicine. In press.

[11] T. Lisman and R. J. Porte, "The role of platelets in liver inflammation and regeneration," Seminars in Thrombosis and Hemostasis, vol. 36, no. 2, pp. 170-174, 2010.

[12] M. Lesurtel, R. Graf, B. Aleil et al., "Platelet-derived serotonin mediates liver regeneration," Science, vol. 312, no. 5770, pp. 104107, 2006.

[13] O. Morales-Ibanez and R. Bataller, "Platelet-derived chemokines: new targets to treat liver fibrosis," Journal of Hepatology, vol. 54, no. 3, pp. 581-583, 2011.

[14] M. M. Zaldivar, K. Pauels, P. Von Hundelshausen et al., "CXC chemokine ligand $4(\mathrm{CXCl} 4)$ is a platelet-derived mediator of experimental liver fibrosis," Hepatology, vol. 51, no. 4, pp. 13451353, 2010.

[15] S. K. Ramaiah and H. Jaeschke, "Role of neutrophils in the pathogenesis of acute inflammatory liver injury," Toxicologic Pathology, vol. 35, no. 6, pp. 757-766, 2007.

[16] R. Ibusuki, H. Uto, S. Arima et al., "Transgenic expression of human neutrophil peptide-1 enhances hepatic fibrosis in mice fed a choline-deficient, L-amino acid-defined diet," Liver International, vol. 33, no. 10, pp. 1549-1556, 2013.

[17] Z. Tan, X. Qian, R. Jiang et al., "IL-17A plays a critical role in the pathogenesis of liver fibrosis through hepatic stellate cell activation," The Journal of Immunology, vol. 191, no. 4, pp. 18351844, 2013.

[18] J. S. Gujral, A. Farhood, M. L. Bajt, and H. Jaeschke, "Neutrophils aggravate acute liver injury during obstructive cholestasis in bile duct-ligated mice," Hepatology, vol. 38, no. 2, pp. 355-363, 2003.
[19] J. M. Saito, M. K. Bostick, C. B. Campe, J. Xu, and J. J. Maher, "Infiltrating neutrophils in bile duct-ligated livers do not promote hepatic fibrosis," Hepatology Research, vol. 25, no. 2, pp. 180-191, 2003.

[20] M. W. Harty, C. S. Muratore, E. F. Papa et al., "Neutrophil depletion blocks early collagen degradation in repairing cholestatic rat livers," The American Journal of Pathology, vol. 176, no. 3, pp. 1271-1281, 2010.

[21] B. Franceschini, G. Ceva-Grimaldi, C. Russo, N. Dioguardi, and F. Grizzi, "The complex functions of mast cells in chronic human liver diseases," Digestive Diseases and Sciences, vol. 51, no. 12, pp. 2248-2256, 2006.

[22] D. J. Farreil, J. E. Hines, A. F. Walls, P. J. Kelly, M. K. Bennett, and A. D. Burt, "Intrahepatic mast cells in chronic liver diseases," Hepatology, vol. 22, no. 4, pp. 1175-1181, 1995.

[23] T. Okazaki, S. Hirota, Z.-D. Xu et al., "Increase of mast cells in the liver and lung may be associated with but not a cause of fibrosis: demonstration using mast cell-deficient Ws/Ws rats," Laboratory Investigation, vol. 78, no. 11, pp. 1431-1438, 1998.

[24] A. Sugihara, T. Tsujimura, Y. Fujita, Y. Nakata, and N. Terada, "Evaluation of role of mast cells in the development of liver fibrosis using mast cell-deficient rats and mice," Journal of Hepatology, vol. 30, no. 5, pp. 859-867, 1999.

[25] J. A. Cairns and A. F. Walls, "Mast cell tryptase stimulates the synthesis of type I collagen in human lung fibroblasts," The Journal of Clinical Investigation, vol. 99, no. 6, pp. 1313-1321, 1997.

[26] B. L. Gruber, R. R. Kew, A. Jelaska et al., "Human mast cells activate fibroblasts: tryptase is a fibrogenic factor stimulating collagen messenger ribonucleic acid synthesis and fibroblast chemotaxis," The Journal of Immunology, vol. 158, no. 5, pp. 2310-2317, 1997.

[27] A. Wehr, C. Baeck, F. Heymann et al., "Chemokine receptor cxcr6-dependent hepatic NK T cell accumulation promotes inflammation and liver fibrosis," The Journal of Immunology, vol. 190, no. 10, pp. 5226-5236, 2013.

[28] S. Ishikawa, K. Ikejima, H. Yamagata et al., "CD1d-restricted natural killer $\mathrm{T}$ cells contribute to hepatic inflammation and fibrogenesis in mice," Journal of Hepatology, vol. 54, no. 6, pp. 1195-1204, 2011.

[29] W.-K. Syn, K. M. Agboola, M. Swiderska et al., "NKT-associated hedgehog and osteopontin drive fibrogenesis in non-alcoholic fatty liver disease," Gut, vol. 61, no. 9, pp. 1323-1329, 2012.

[30] C. De Lalla, G. Galli, L. Aldrighetti et al., "Production of profibrotic cytokines by invariant NKT cells characterizes cirrhosis progression in chronic viral hepatitis," Journal of Immunology, vol. 173, no. 2, pp. 1417-1425, 2004.

[31] B. Gao, S. Radaeva, and O. Park, "Liver natural killer and natural killer T cells: immunobiology and emerging roles in liver diseases," Journal of Leukocyte Biology, vol. 86, no. 3, pp. 513528, 2009.

[32] B. Gao, S. Radaeva, and W.-I. Jeong, "Activation of natural killer cells inhibits liver fibrosis: a novel strategy to treat liver fibrosis," Expert Review of Gastroenterology \& Hepatology, vol. 1, no. 1, pp. 173-180, 2007.

[33] B. Gao and S. Radaeva, "Natural killer and natural killer T cells in liver fibrosis," Biochimica et Biophysica Acta-Molecular Basis of Disease, vol. 1832, no. 7, pp. 1061-1069, 2013.

[34] S. Radaeva, R. Sun, B. Jaruga, V. T. Nguyen, Z. Tian, and B. Gao, "Natural killer cells ameliorate liver fibrosis by killing activated stellate cells in NKG2D-dependent and tumor necrosis factor-related apoptosis-inducing ligand-dependent manners," Gastroenterology, vol. 130, no. 2, pp. 435-452, 2006. 
[35] A. Glässner, M. Eisenhardt, B. Krämer et al., "NK cells from HCV-infected patients effectively induce apoptosis of activated primary human hepatic stellate cells in a TRAIL-, FasL- and NKG2D-dependent manner," Laboratory Investigation, vol. 92, pp. 967-977, 2012.

[36] G. S. Baroni, L. D’Ambrosio, P. Curto et al., "Interferon gamma decreases hepatic stellate cell activation and extracellular matrix deposition in rat liver fibrosis," Hepatology, vol. 23, no. 5, pp. 1189-1199, 1996.

[37] W.-I. Jeong, O. Park, S. Radaeva, and B. Gao, "STAT1 inhibits liver fibrosis in mice by inhibiting stellate cell proliferation and stimulating NK cell cytotoxicity," Hepatology, vol. 44, no. 6, pp. 1441-1451, 2006.

[38] P. Ramachandran and J. P. Iredale, "Liver fibrosis: a bidirectional model fibrogenesis and resolution," The Quarterly Journal of Medicine, vol. 105, pp. 813-817, 2012.

[39] M. Imamura, T. Ogawa, Y. Sasaguri, K. Chayama, and H. Ueno, "Suppression of macrophage infiltration inhibits activation of hepatic stellate cells and liver fibrogenesis in rats," Gastroenterology, vol. 128, no. 1, pp. 138-146, 2005.

[40] J. S. Duffield, S. J. Forbes, C. M. Constandinou et al., "Selective depletion of macrophages reveals distinct, opposing roles during liver injury and repair," The Journal of Clinical Investigation, vol. 115, no. 1, pp. 56-65, 2005.

[41] C. Mitchell, D. Couton, J.-P. Couty et al., "Dual role of CCR2 in the constitution and the resolution of liver fibrosis in mice," The American Journal of Pathology, vol. 174, no. 5, pp. 1766-1775, 2009.

[42] F. Heymann, L. Hammerich, D. Storch et al., "Hepatic macrophage migration and differentiation critical for liver fibrosis is mediated by the chemokine receptor $\mathrm{C}-\mathrm{C}$ motif chemokine receptor 8 in mice," Hepatology, vol. 55, no. 3, pp. 898-909, 2012.

[43] S. Galastri, E. Zamara, S. Milani et al., "Lack of CC chemokine ligand 2 differentially affects inflammation and fibrosis according to the genetic background in a murine model of steatohepatitis," Clinical Science, vol. 123, no. 7, pp. 459-471, 2012.

[44] T. A. Wynn and L. Barron, "Macrophages: master regulators of inflammation and fibrosis," Seminars in Liver Disease, vol. 30, no. 3, pp. 245-257, 2010.

[45] S. L. Friedman, "Hepatic stellate cells: protean, multifunctional, and enigmatic cells of the liver," Physiological Reviews, vol. 88, no. 1, pp. 125-172, 2008.

[46] Y. Sunami, F. Leithäuser, S. Gul et al., "Hepatic activation of $\mathrm{IKK} / \mathrm{NF} \kappa \mathrm{B}$ signaling induces liver fibrosis via macrophagemediated chronic inflammation," Hepatology, vol. 56, no. 3, pp. 1117-1128, 2012.

[47] S. L. Friedman, "Mac the knife? Macrophages-the doubleedged sword of hepatic fibrosis," The Journal of Clinical Investigation, vol. 115, no. 1, pp. 29-32, 2005.

[48] J. A. Thomas, C. Pope, D. Wojtacha et al., "Macrophage therapy for murine liver fibrosis recruits host effector cells improving fibrosis, regeneration, and function," Hepatology, vol. 53, no. 6, pp. 2003-2015, 2011.

[49] A. M. Elsharkawy, F. Oakley, and D. A. Mann, "The role and regulation of hepatic stellate cell apoptosis in reversal of liver fibrosis," Apoptosis, vol. 10, no. 5, pp. 927-939, 2005.

[50] R. Fischer, A. Cariers, R. Reinehr, and D. Häussinger, "Caspase 9-dependent killing of hepatic stellate cells by activated Kupffer cells," Gastroenterology, vol. 123, no. 3, pp. 845-861, 2002.

[51] K. R. Karlmark, R. Weiskirchen, H. W. Zimmermann et al., "Hepatic recruitment of the inflammatory $\mathrm{Grl}^{+}$monocyte subset upon liver injury promotes hepatic fibrosis," Hepatology, vol. 50, no. 1, pp. 261-274, 2009.

[52] R. Bataller and D. A. Brenner, "Liver fibrosis," Journal of Clinical Investigation, vol. 115, no. 2, pp. 209-218, 2005.

[53] N. Muhanna, A. Horani, S. Doron, and R. Safadi, "Lymphocytehepatic stellate cell proximity suggests a direct interaction," Clinical \& Experimental Immunology, vol. 148, no. 2, pp. 338347, 2007.

[54] R. Safadi, M. Ohta, C. E. Alvarez et al., "Immune stimulation of hepatic fibrogenesis by CD 8 cells and attenuation by transgenic interleukin-10 from hepatocytes," Gastroenterology, vol. 127, no. 3, pp. 870-882, 2004.

[55] O. Viñas, R. Bataller, P. Sancho-Bru et al., "Human hepatic stellate cells show features of antigen-presenting cells and stimulate lymphocyte proliferation," Hepatology, vol. 38, no. 4, pp. 919-929, 2003.

[56] N. Muhanna, S. Doron, O. Wald et al., "Activation of hepatic stellate cells after phagocytosis of lymphocytes: a novel pathway of fibrogenesis," Hepatology, vol. 48, no. 3, pp. 963-977, 2008.

[57] A. M. Gressner and M. G. Bachem, "Cellular sources of noncollagenous matrix proteins: role of fat-storing cells in fibrogenesis," Seminars in Liver Disease, vol. 10, no. 1, pp. 30-46, 1990.

[58] Z. Shi, A. E. Wakil, and D. C. Rockey, "Strain-specific differences in mouse hepatic wound healing are mediated by divergent $\mathrm{T}$ helper cytokine responses," Proceedings of the National Academy of Sciences of the United States of America, vol. 94, no. 20, pp. 10663-10668, 1997.

[59] T. A. Wynn, "Fibrotic disease and the $\mathrm{T}_{\mathrm{H}} 1 / \mathrm{T}_{\mathrm{H}} 2$ paradigm," Nature Reviews Immunology, vol. 4, no. 8, pp. 583-594, 2004.

[60] T. I. Novobrantseva, G. R. Majeau, A. Amatucci et al., "Attenuated liver fibrosis in the absence of B cells," Journal of Clinical Investigation, vol. 115, no. 11, pp. 3072-3082, 2005.

[61] R. K. Bhogal and C. A. Bona, "B cells: no longer bystanders in liver fibrosis," The Journal of Clinical Investigation, vol. 115, no. 11, pp. 2962-2965, 2005.

[62] B.-B. Wang, J.-Y. Cheng, H.-H. Gao, Y. Zhang, Z.-N. Chen, and H. Bian, "Hepatic stellate cells in inflammation-fibrosiscarcinoma axis," Anatomical Record, vol. 293, no. 9, pp. 14921496, 2010.

[63] S. L. Friedman, "Mechanisms of hepatic fibrogenesis," Gastroenterology, vol. 134, no. 6, pp. 1655-1669, 2008.

[64] Y.-J. Liang, J. Luo, Q. Lu et al., "Gene profile of Chemokines on hepatic stellate cells of schistosome-infected mice and antifibrotic roles of CXCL9/10 on liver non-parenchymal cells," PLoS ONE, vol. 7, no. 8, Article ID e42490, 2012.

[65] K. Bourd-Boittin, L. Basset, D. Bonnier, A. L'Helgoualc'H, M. Samson, and N. Théret, "CX3CL1/fractalkine shedding by human hepatic stellate cells: contribution to chronic inflammation in the liver," Journal of Cellular and Molecular Medicine, vol. 13, no. 8A, pp. 1526-1535, 2009.

[66] T. Knittel, C. Dinter, D. Kobold et al., "Expression and regulation of cell adhesion molecules by hepatic stellate cells (HSC) of rat liver: involvement of HSC in recruitment of inflammatory cells during hepatic tissue repair," The American Journal of Pathology, vol. 154, no. 1, pp. 153-167, 1999.

[67] J. A. Fallowfield, "Therapeutic targets in liver fibrosis," The American Journal of Physiology-Gastrointestinal and Liver Physiology, vol. 300, no. 5, pp. G709-G715, 2011.

[68] S. L. Friedman, "Liver fibrosis-from bench to bedside," Journal of Hepatology, vol. 38, no. 1, pp. S38-S53, 2003. 
[69] H. Hayashi and T. Sakai, "Animal models for the study of liver fibrosis: new insights from knockout mouse models," American Journal of Physiology-Gastrointestinal and Liver Physiology, vol. 300, no. 5, pp. G729-G738, 2011.

[70] J. R. Klune, R. Dhupar, J. Cardinal, T. R. Billiar, A. Tsung, and A. Tsung, “HMGB1:Endogenous danger signaling," Molecular Medicine, vol. 14, no. 7-8, pp. 476-484, 2008.

[71] R. Dhupar, J. R. Klune, J. Evankovich et al., "Interferon regulatory factor 1 mediates acetylation and release of high mobility group box 1 from hepatocytes during murine liver ischemiareperfusion injury," Shock, vol. 35, no. 3, pp. 293-301, 2011.

[72] G. P. Sims, D. C. Rowe, S. T. Rietdijk, R. Herbst, and A. J. Coyle, "HMGB1 and RAGE in inflammation and cancer," Annual Review of Immunology, vol. 28, pp. 367-388, 2010.

[73] C. Wang, H. Nie, K. Li et al., "Curcumin inhibits HMGB1 releasing and attenuates concanavalin A-induced hepatitis in mice," European Journal of Pharmacology, vol. 697, no. 1-3, pp. 152-157, 2012.

[74] C.-T. Tu, Q.-Y. Yao, B.-L. Xu, and S.-C. Zhang, "Curcumin protects against concanavalin a-induced hepatitis in mice through inhibiting the cytoplasmic translocation and expression of high mobility group Box 1," Inflammation, vol. 36, no. 1, pp. 206-215, 2013.

[75] M. Ogiku, H. Kono, M. Hara, M. Tsuchiya, and H. Fujii, "Glycyrrhizin prevents liver injury by inhibition of highmobility group box 1 production by kupffer cells after ischemiareperfusion in rats," Journal of Pharmacology and Experimental Therapeutics, vol. 339, no. 1, pp. 93-98, 2011.

[76] N. Yun, J.-W. Kang, and S.-M. Lee, "Protective effects of chlorogenic acid against ischemia/reperfusion injury in rat liver: molecular evidence of its antioxidant and anti-inflammatory properties," Journal of Nutritional Biochemistry, vol. 23, no. 10, pp. 1249-1255, 2012.

[77] C.-T. Tu, Q.-Y. Yao, B.-L. Xu, J.-Y. Wang, C.-H. Zhou, and S.-C. Zhang, "Protective effects of curcumin against hepatic fibrosis induced by carbon tetrachloride: modulation of high-mobility group box 1, Toll-like receptor 4 and 2 expression," Food and Chemical Toxicology, vol. 50, no. 9, pp. 3343-3351, 2012.

[78] S. L. Deshmane, S. Kremlev, S. Amini, and B. E. Sawaya, "Monocyte chemoattractant protein-1 (MCP-1): an overview," Journal of Interferon and Cytokine Research, vol. 29, no. 6, pp. 313-325, 2009.

[79] A. A. Nanji, K. Jokelainen, G. L. Tipoe, A. Rahemtulla, P. Thomas, and A. J. Dannenberg, "Curcumin prevents alcoholinduced liver disease in rats by inhibiting the expression of NF- $\kappa$ B-dependent genes," The American Journal of PhysiologyGastrointestinal and Liver Physiology, vol. 284, no. 2, pp. G321G327, 2003.

[80] I. A. Leclercq, G. C. Farrell, C. Sempoux, A. D. Peña, and Y. Horsmans, "Curcumin inhibits NF-kappaB activation and reduces the severity of experimental steatohepatitis in mice," Journal of Hepatology, vol. 41, no. 6, pp. 926-934, 2004.

[81] F. Vizzutti, A. Provenzano, S. Galastri et al., "Curcumin limits the fibrogenic evolution of experimental steatohepatitis," Laboratory Investigation, vol. 90, no. 1, pp. 104-115, 2010.

[82] J.-J. Kuo, H.-H. Chang, T.-H. Tsai, and T.-Y. Lee, "Positive effect of curcumin on inflammation and mitochondrial dysfunction in obese mice with liver steatosis," International Journal of Molecular Medicine, vol. 30, no. 3, pp. 673-679, 2012.

[83] X. Lv, Z. Chen, J. Li et al., "Caffeine protects against alcoholic liver injury by attenuating inflammatory response and oxidative stress," Inflammation Research, vol. 59, no. 8, pp. 635-645, 2010.
[84] Y.-H. Paik, Y. J. Yoon, H. C. Lee et al., "Antifibrotic effects of magnesium lithospermate $\mathrm{B}$ on hepatic stellate cells and thioacetamide-induced cirrhotic rats," Experimental \& Molecular Medicine, vol. 43, no. 6, pp. 341-349, 2011.

[85] Y. H. Oo, S. Shetty, and D. H. Adams, "The role of chemokines in the recruitment of lymphocytes to the liver," Digestive Diseases, vol. 28, no. 1, pp. 31-44, 2010.

[86] C.-T. Tu, B. Han, H.-C. Liu, and S.-C. Zhang, "Curcumin protects mice against Concanavalin A-induced hepatitis by inhibiting intrahepatic intercellular adhesion molecule-1 (ICAM-1) and CXCL10 expression," Molecular and Cellular Biochemistry, vol. 358, no. 1-2, pp. 53-60, 2011.

[87] L. Cao, Y. Zou, J. Zhu, X. Fan, and J. Li, "Ginsenoside Rg1 attenuates concanavalin A-induced hepatitis in mice through inhibition of cytokine secretion and lymphocyte infiltration," Molecular and Cellular Biochemistry, vol. 380, no. 1-2, pp. 203210, 2013.

[88] Y.-L. Lin, Y.-C. Hsu, Y.-T. Chiu, and Y.-T. Huang, "Antifibrotic effects of a herbal combination regimen on hepatic fibrotic rats," Phytotherapy Research, vol. 22, no. 1, pp. 69-76, 2008.

[89] Y. Xu, D. Feng, Y. Wang, S. Lin, and L. Xu, "Sodium tanshinone IIA sulfonate protects mice from ConA-induced hepatitis via inhibiting NF- $\kappa$ B and IFN- $\gamma /$ STAT1 pathways," Journal of Clinical Immunology, vol. 28, no. 5, pp. 512-519, 2008.

[90] R. Bruck, M. Ashkenazi, S. Weiss et al., "Prevention of liver cirrhosis in rats by curcumin," Liver International, vol. 27, no. 3, pp. 373-383, 2007.

[91] C.-T. Tu, B. Han, Q.-Y. Yao, Y.-A. Zhang, H.-C. Liu, and S.C. Zhang, "Curcumin attenuates Concanavalin A-induced liver injury in mice by inhibition of Toll-like receptor (TLR) 2, TLR4 and TLR9 expression," International Immunopharmacology, vol. 12, no. 1, pp. 151-157, 2012.

[92] N. Tsuruoka, K. Abe, K. Wake et al., "Hepatic protection by glycyrrhizin and inhibition of iNOS expression in concanavalin A-induced liver injury in mice," Inflammation Research, vol. 58, no. 9, pp. 593-599, 2009.

[93] A. K. Singh, H. Mani, P. Seth et al., "Picroliv preconditioning protects the rat liver against ischemia-reperfusion injury," European Journal of Pharmacology, vol. 395, no. 3, pp. 229-239, 2000.

[94] J.-F. Ye, H. Zhu, Z.-F. Zhou et al., "Protective mechanism of andrographolide against carbon tetrachloride- induced acute liver injury in mice," Biological and Pharmaceutical Bulletin, vol. 34, no. 11, pp. 1666-1670, 2011.

[95] M.-E. Wang, Y.-C. Chen, I.-S. Chen, S.-C. Hsieh, S.-S. Chen, and C.-H. Chiu, "Curcumin protects against thioacetamideinduced hepatic fibrosis by attenuating the inflammatory response and inducing apoptosis of damaged hepatocytes," Journal of Nutritional Biochemistry, vol. 23, no. 10, pp. 1352-1366, 2012.

[96] D.-H. Jeong, G.-P. Lee, W.-I. Jeong et al., "Alterations of mast cells and TGF- $\beta 1$ on the silymarin treatment for CCI4-induced hepatic fibrosis," World Journal of Gastroenterology, vol. 11, no. 8, pp. 1141-1148, 2005.

[97] N. M. El-Lakkany, O. A. Hammam, W. H. El-Maadawy, A. A. Badawy, A. A. Ain-Shoka, and F. A. Ebeid, "Anti-inflammatory/anti-fibrotic effects of the hepatoprotective silymarin and the Schistosomicide praziquantel against Schistosoma mansoni-induced liver fibrosis," Parasites and Vectors, vol. 5, no. 1, article 9, 2012.

[98] G. Pener, L. Kabasakal, M. Yüksel, N. Gedik, and Ý. Alican, "Hepatic fibrosis in biliary-obstructed rats is prevented by 
Ginkgo biloba treatment," World Journal of Gastroenterology, vol. 11, no. 35, pp. 5444-5449, 2005.

[99] J.-G. Liu, Y.-R. Ding, and S.-L. Yang, "Effect of salvianolic acid B on CD14 expression in rats with liver fibrosis," Zhongguo Zhong Xi Yi Jie He Za Zhi, vol. 31, no. 4, pp. 547-551, 2011.

[100] C.-T. Tu, J. Li, F.-P. Wang, L. Li, J.-Y. Wang, and W. Jiang, "Glycyrrhizin regulates CD4+T cell response during liver fibrogenesis via JNK, ERK and PI3K/AKT pathway," International Immunopharmacology, vol. 14, no. 4, pp. 410-421, 2012.

[101] D. N. Roy, G. Sen, K. D. Chowdhury, and T. Biswas, "Combination therapy with andrographolide and d-penicillamine enhanced therapeutic advantage over monotherapy with $\mathrm{D}$ penicillamine in attenuating fibrogenic response and cell death in the periportal zone of liver in rats during copper toxicosis," Toxicology and Applied Pharmacology, vol. 250, no. 1, pp. 54-68, 2011.

[102] S. G. Shim, D. W. Jun, E. K. Kim et al., "Caffeine attenuates liver fibrosis via defective adhesion of hepatic stellate cells in cirrhotic model," Journal of Gastroenterology and Hepatology, vol. 28, no. 12, pp. 1877-1884, 2013.

[103] X.-Y. Qin, T. Li, L. Yan, Q.-S. Liu, and Y. Tian, “Tanshinone IIA protects against immune-mediated liver injury through activation of T-cell subsets and regulation of cytokines," Immunopharmacology and Immunotoxicology, vol. 32, no. 1, pp. 51-55, 2010.

[104] T. Lawrence, "The nuclear factor NF-kappaB pathway in inflammation," Cold Spring Harbor Perspectives in Biology, vol. 1, no. 6, Article ID a001651, 2009.

[105] X.-G. Sun, X.-Q. Fu, H.-B. Cai et al., "Proteomic analysis of protective effects of polysaccharides from Salvia miltiorrhiza against immunological liver injury in mice," Phytotherapy Research, vol. 25, no. 7, pp. 1087-1094, 2011.

[106] J.-Y. Wan, X. Gong, L. Zhang, H.-Z. Li, Y.-F. Zhou, and Q.$\mathrm{X}$. Zhou, "Protective effect of baicalin against Lipopolysaccharide/d-galactosamine-induced liver injury in mice by upregulation of Heme oxygenase-1," European Journal of Pharmacology, vol. 587, no. 1-3, pp. 302-308, 2008.

[107] S.-J. Kim, Y.-J. Moon, and S.-M. Lee, "Protective effects of baicalin against ischemia/reperfusion injury in rat liver," Journal of Natural Products, vol. 73, no. 12, pp. 2003-2008, 2010.

[108] B. Shen, J. Yu, S. Wang et al., "Phyllanthus urinaria ameliorates the severity of nutritional steatohepatitis both in vitro and in vivo," Hepatology, vol. 47, no. 2, pp. 473-483, 2008.

[109] K. S. Kang, H. Y. Kim, N. Yamabe, J. H. Park, and T. Yokozawa, "Preventive effect of 20(S)-ginsenoside Rg3 against lipopolysaccharide-induced hepatic and renal injury in rats," Free Radical Research, vol. 41, no. 10, pp. 1181-1188, 2007.

[110] S.-J. Wu, K.-W. Tam, Y.-H. Tsai, C.-C. Chang, and J. C.-J. Chao, "Curcumin and saikosaponin A inhibit chemical-induced liver inflammation and fibrosis in rats," The American Journal of Chinese Medicine, vol. 38, no. 1, pp. 99-111, 2010.

[111] A. R. Bassiouny, A. Zaky, F. Fawky, and K. M. Kandeel, "Alteration of AP-endonucleasel expression in curcumin-treated fibrotic rats," Annals of Hepatology, vol. 10, no. 4, pp. 516-530, 2011.

[112] S.-Q. Liu, J.-P. Yu, L. He, H.-G. Yu, and H.-S. Luo, "Effects of nuclear factor kappaB and transforming growth factor betal in the anti-liver fibrosis process using Ginkgo biloba extract," Zhonghua Gan Zang Bing Za Zhi, vol. 13, no. 12, pp. 903-907, 2005.

[113] Z.-Y. Zhou, S.-Q. Tang, Y.-M. Zhou, H.-S. Luo, and X. Liu, "Antioxidant and hepatoprotective effects of extract of ginkgo biloba in rats of non-alcoholic steatohepatitis," Saudi Medical Journal, vol. 31, no. 10, pp. 1114-1118, 2010.

[114] R. Wang, X.-Y. Yu, Z.-Y. Guo, Y.-J. Wang, Y. Wu, and Y.-F. Yuan, "Inhibitory effects of salvianolic acid $\mathrm{B}$ on $\mathrm{CCl}_{4}$-induced hepatic fibrosis through regulating NF- $\kappa \mathrm{B} / \mathrm{I} \kappa \mathrm{B} \alpha$ signaling," Journal of Ethnopharmacology, vol. 144, no. 3, pp. 592-598, 2012.

[115] J.-Y. Wang, J.-S. Guo, H. Li, S.-L. Liu, and M. A. Zern, "Inhibitory effect of glycyrrhizin on NF- $\kappa$ B binding activity in $\mathrm{CCl}(4-)$ plus ethanol-induced liver cirrhosis in rats," Liver, vol. 18, no. 3, pp. 180-185, 1998.

[116] S.-J. Kim and S.-M. Lee, "Effect of baicalin on toll-like receptor 4-mediated ischemia/reperfusion inflammatory responses in alcoholic fatty liver condition," Toxicology and Applied Pharmacology, vol. 258, no. 1, pp. 43-50, 2012.

[117] S.-S. Dang, B.-F. Wang, Y.-A. Cheng, P. Song, Z.-G. Liu, and Z.-F. Li, "Inhibitory effects of saikosaponin-D on $\mathrm{CCl}_{4}$-induced hepatic fibrogenesis in rats," World Journal of Gastroenterology, vol. 13, no. 4, pp. 557-563, 2007.

[118] H. Shi, L. Dong, J. Jiang et al., "Chlorogenic acid reduces liver inflammation and fibrosis through inhibition of toll-like receptor 4 signaling pathway," Toxicology, vol. 303, pp. 107-114, 2013.

[119] R. van den Berg, G. R. M. M. Haenen, H. van den Berg, and A. Bast, "Transcription factor NF- $\kappa \mathrm{B}$ as a potential biomarker for oxidative stress," British Journal of Nutrition, vol. 86, pp. S121S127, 2001.

[120] R. F. Schwabe, E. Seki, and D. A. Brenner, "Toll-like receptor signaling in the liver," Gastroenterology, vol. 130, no. 6, pp. 18861900, 2006.

[121] A. M. Piccinini and K. S. Midwood, "DAMPening inflammation by modulating TLR signalling," Mediators of Inflammation, vol. 2010, Article ID 672395, 21 pages, 2010.

[122] F.-P. Wang, L. Li, J. Li, J.-Y. Wang, L.-Y. Wang, and W. Jiang, "High mobility group box-1 promotes the proliferation and migration of hepatic stellate cells via TLR4-dependent signal pathways of PI3K/Akt and JNK," PLoS ONE, vol. 8, no. 5, Article ID e64373, 2013.

[123] Q. Wang, R. Dziarski, C. J. Kirschning, M. Muzio, and D. Gupta, "Micrococci and peptidoglycan activate TLR2 $\rightarrow$ MyD88 $\rightarrow$ $\mathrm{IRAK} \rightarrow \mathrm{TRAF} \rightarrow \mathrm{NIK} \rightarrow \mathrm{IKK} \rightarrow \mathrm{NF}-\mathrm{kappaB}$ signal transduction pathway that induces transcription of interleukin-8," Infection and Immunity, vol. 69, no. 4, pp. 2270-2276, 2001.

[124] A. Paine, B. Eiz-Vesper, R. Blasczyk, and S. Immenschuh, "Signaling to heme oxygenase- 1 and its anti-inflammatory therapeutic potential," Biochemical Pharmacology, vol. 80, no. 12, pp. 1895-1903, 2010

[125] M. L. Ferrándiz and I. Devesa, "Inducers of heme oxygenase-1," Current Pharmaceutical Design, vol. 14, no. 5, pp. 473-486, 2008.

[126] K. Tsoyi, Y. L. Tae, S. L. Young et al., "Heme-oxygenase-1 induction and carbon monoxide-releasing molecule inhibit lipopolysaccharide (LPS)-induced high-mobility group box 1 release in vitro and improve survival of mice in LPS- and cecal ligation and puncture-induced sepsis model in vivo," Molecular Pharmacology, vol. 76, no. 1, pp. 173-182, 2009.

[127] R.-H. Shih and C.-M. Yang, "Induction of heme oxygenase1 attenuates lipopolysaccharide-induced cyclooxygenase- 2 expression in mouse brain endothelial cells," Journal of Neuroinflammation, vol. 7, article 86, 2010.

[128] C.-H. Lee, S.-W. Park, Y. S. Kim et al., "Protective mechanism of glycyrrhizin on acute liver injury induced by carbon tetrachloride in mice," Biological and Pharmaceutical Bulletin, vol. 30, no. 10, pp. 1898-1904, 2007. 
[129] S.-W. Park, C.-H. Lee, S. K. Yeong et al., "Protective effect of baicalin against carbon tetrachloride-induced acute hepatic injury in mice," Journal of Pharmacological Sciences, vol. 106, no. 1, pp. 136-143, 2008.

[130] M.-K. Tsai, Y.-L. Lin, and Y.-T. Huang, "Effects of salvianolic acids on oxidative stress and hepatic fibrosis in rats," Toxicology and Applied Pharmacology, vol. 242, no. 2, pp. 155-164, 2010.

[131] M. Kim, S.-G. Yang, J. M. Kim, J.-W. Lee, Y. S. Kim, and J. I. Lee, "Silymarin suppresses hepatic stellate cell activation in a dietary rat model of non-alcoholic steatohepatitis: analysis of isolated hepatic stellate cells," International Journal of Molecular Medicine, vol. 30, no. 3, pp. 473-479, 2012.

[132] Z. Song, I. Deaciuc, M. Song et al., "Silymarin protects against acute ethanol-induced hepatotoxicity in mice," Alcoholism: Clinical and Experimental Research, vol. 30, no. 3, pp. 407-413, 2006.

[133] R. M. Chávez-Morales, F. Jaramillo-Juárez, F. A. Posadas Del Río, M. A. Reyes-Romero, M. L. Rodríguez-Vázquez, and M. C. Martínez-Saldaña, "Protective effect of Ginkgo biloba extract on liver damage by a single dose of $\mathrm{CCl}_{4}$ in male rats," Human and Experimental Toxicology, vol. 30, no. 3, pp. 209-216, 2011.

[134] Z.-M. Wu, T. Wen, Y.-F. Tan, Y. Liu, F. Ren, and H. Wu, "Effects of salvianolic acid A on oxidative stress and liver injury induced by carbon tetrachloride in rats," Basic \& Clinical Pharmacology \& Toxicology, vol. 100, no. 2, pp. 115-120, 2007.

[135] M. Abe, F. Akbar, A. Hasebe, N. Horiike, and M. Onji, "Glycyrrhizin enhances interleukin-10 production by liver dendritic cells in mice with hepatitis," Journal of Gastroenterology, vol. 38, no. 10, pp. 962-967, 2003.

[136] T. Yoshida, K. Abe, T. Ikeda et al., "Inhibitory effect of glycyrrhizin on lipopolysaccharide and d-galactosamine-induced mouse liver injury," European Journal of Pharmacology, vol. 576, no. 1-3, pp. 136-142, 2007.

[137] L.-L. Liu, L.-K. Gong, H. Wang et al., "Baicalin protects mouse from Concanavalin A-induced liver injury through inhibition of cytokine production and hepatocyte apoptosis," Liver International, vol. 27, no. 4, pp. 582-591, 2007.

[138] P. Pramyothin, P. Samosorn, S. Poungshompoo, and C. Chaichantipyuth, "The protective effects of Phyllanthus emblica Linn. extract on ethanol induced rat hepatic injury," Journal of Ethnopharmacology, vol. 107, no. 3, pp. 361-364, 2006.

[139] V. Suresh and V. V. Asha, "Preventive effect of ethanol extract of Phyllanthus rheedii Wight. on d-galactosamine induced hepatic damage in Wistar rats," Journal of Ethnopharmacology, vol. 116, no. 3, pp. 447-453, 2008.

[140] P. Pramyothin, C. Ngamtin, S. Poungshompoo, and C. Chaichantipyuth, "Hepatoprotective activity of Phyllanthus amarus Schum. et. Thonn. extract in ethanol treated rats: in vitro and in vivo studies," Journal of Ethnopharmacology, vol. 114, no. 2, pp. 169-173, 2007.

[141] R. Domitrović, H. Jakovac, and G. Blagojević, "Hepatoprotective activity of berberine is mediated by inhibition of TNF- $\alpha$, COX-2, and iNOS expression in $\mathrm{CCl}_{4}$-intoxicated mice," Toxicology, vol. 280, no. 1-2, pp. 33-43, 2011.

[142] D. H. Kim, J. H. Chung, J. S. Yoon et al., "Ginsenoside Rd inhibits the expressions of iNOS and COX-2 by suppressing NF$\kappa$ B in LPS-stimulated RAW264.7 cells and mouse liver," Journal of Ginseng Research, vol. 37, no. 1, pp. 54-63, 2013.

[143] I. Akashi, K. Kagami, T. Hirano, and K. Oka, "Protective effects of coffee-derived compounds on lipopolysaccharide/Dgalactosamine induced acute liver injury in rats," Journal of Pharmacy and Pharmacology, vol. 61, no. 4, pp. 473-478, 2009.
[144] Y. Fu, S. Zheng, J. Lin, J. Ryerse, and A. Chen, "Curcumin protects the rat liver from $\mathrm{CCl}_{4}$-caused injury and fibrogenesis by attenuating oxidative stress and suppressing inflammation," Molecular Pharmacology, vol. 73, no. 2, pp. 399-409, 2008.

[145] S. Bisht, M. A. Khan, M. Bekhit et al., "A polymeric nanoparticle formulation of curcumin (NanoCurc) ameliorates CCl 4induced hepatic injury and fibrosis through reduction of proinflammatory cytokines and stellate cell activation," Laboratory Investigation, vol. 91, no. 9, pp. 1383-1395, 2011.

[146] G. Yuan, Z. Gong, J. Li, and X. Li, "Ginkgo biloba extract protects against alcohol-induced liver injury in rats," Phytotherapy Research, vol. 21, no. 3, pp. 234-238, 2007.

[147] H. Wang, X.-P. Chen, and F.-Z. Qiu, "Salviae miltiorrhizae ameliorates cirrhosis and portal hypertension by inhibiting nitric oxide in cirrhotic rats," Hepatobiliary and Pancreatic Diseases International, vol. 2, no. 3, pp. 391-396, 2003.

[148] Y. Zhang, Y. Xie, Y. Gao et al., "Multitargeted inhibition of hepatic fibrosis in chronic iron-overloaded mice by Salvia miltiorrhiza," Journal of Ethnopharmacology, vol. 148, no. 2, pp. 671681, 2013.

[149] X.-D. Peng, L.-L. Dai, C.-Q. Huang, C.-M. He, and L.-J. Chen, "Correlation between anti-fibrotic effect of baicalin and serum cytokines in rat hepatic fibrosis," World Journal of Gastroenterology, vol. 15, no. 37, pp. 4720-4725, 2009.

[150] R. Domitrović, H. Jakovac, V. V. Marchesi, and B. Blažeković, "Resolution of liver fibrosis by isoquinoline alkaloid berberine in $\mathrm{CCl}_{4}$-intoxicated mice is mediated by suppression of oxidative stress and upregulation of MMP-2 expression," Journal of Medicinal Food, vol. 16, no. 6, pp. 518-528, 2013.

[151] X.-D. Peng, L.-L. Dai, C.-Q. Huang, C.-M. He, B. Yang, and L.-J. Chen, "Relationship between anti-fibrotic effect of Panax notoginseng saponins and serum cytokines in rat hepatic fibrosis," Biochemical and Biophysical Research Communications, vol. 388, no. 1, pp. 31-34, 2009.

[152] T.-Y. Lee, K.-C. Lee, and H.-H. Chang, "Modulation of the cannabinoid receptors by andrographolide attenuates hepatic apoptosis following bile duct ligation in rats with fibrosis," Apoptosis, vol. 15, no. 8, pp. 904-914, 2010.

[153] J.-W. Shin, J.-H. Wang, J.-K. Kang, and C.-G. Son, "Experimental evidence for the protective effects of coffee against liver fibrosis in SD rats," Journal of the Science of Food and Agriculture, vol. 90, no. 3, pp. 450-455, 2010.

[154] P. Vitaglione, F. Morisco, G. Mazzone et al., "Coffee reduces liver damage in a rat model of steatohepatitis: the underlying mechanisms and the role of polyphenols and melanoidins," Hepatology, vol. 52, no. 5, pp. 1652-1661, 2010. 


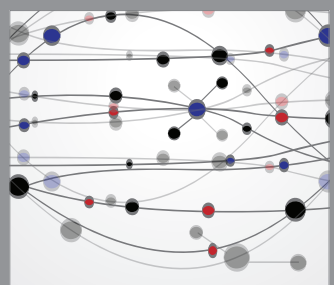

The Scientific World Journal
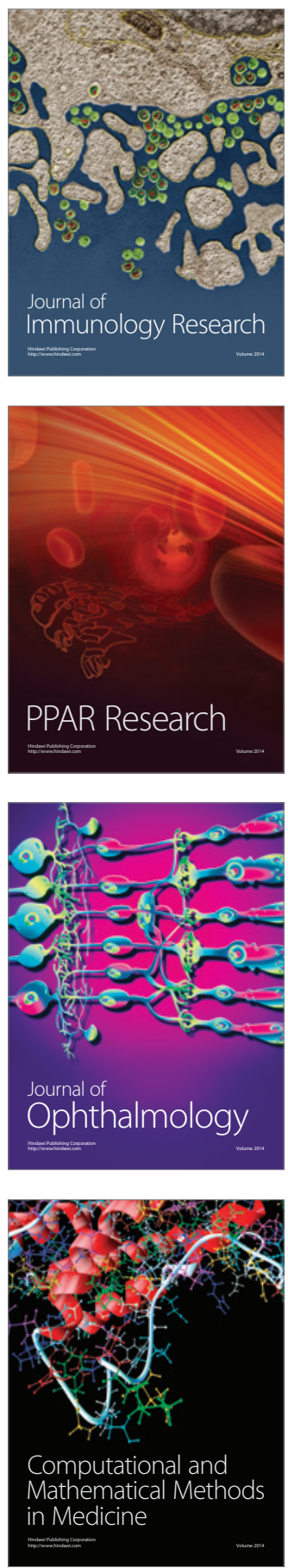

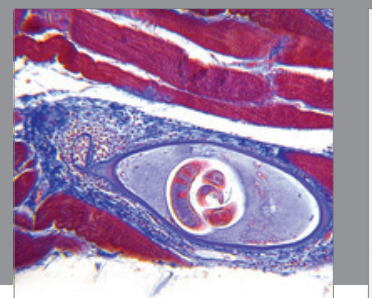

Gastroenterology

Research and Practice
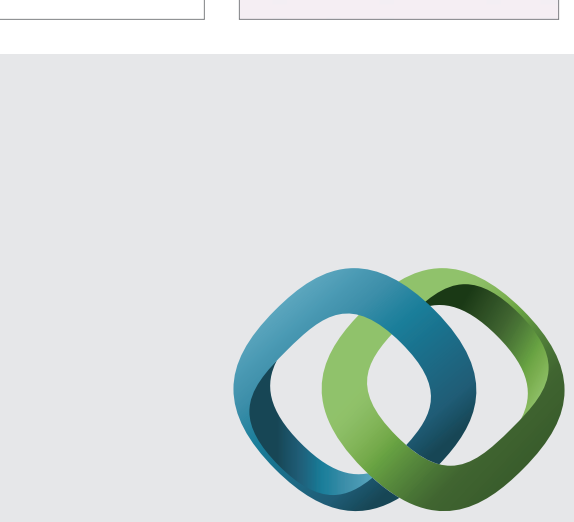

\section{Hindawi}

Submit your manuscripts at

http://www.hindawi.com
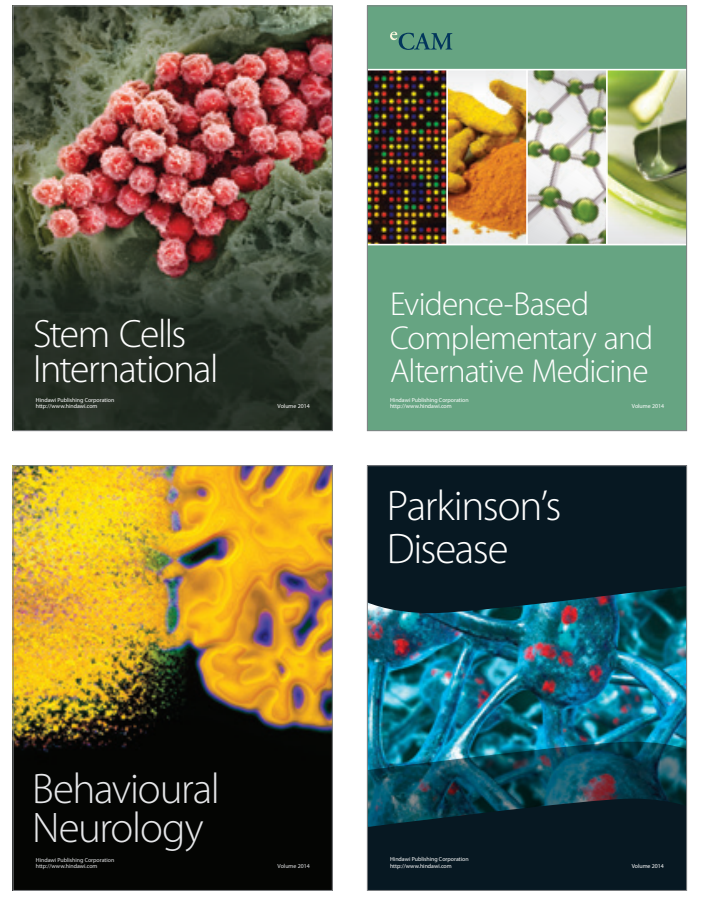
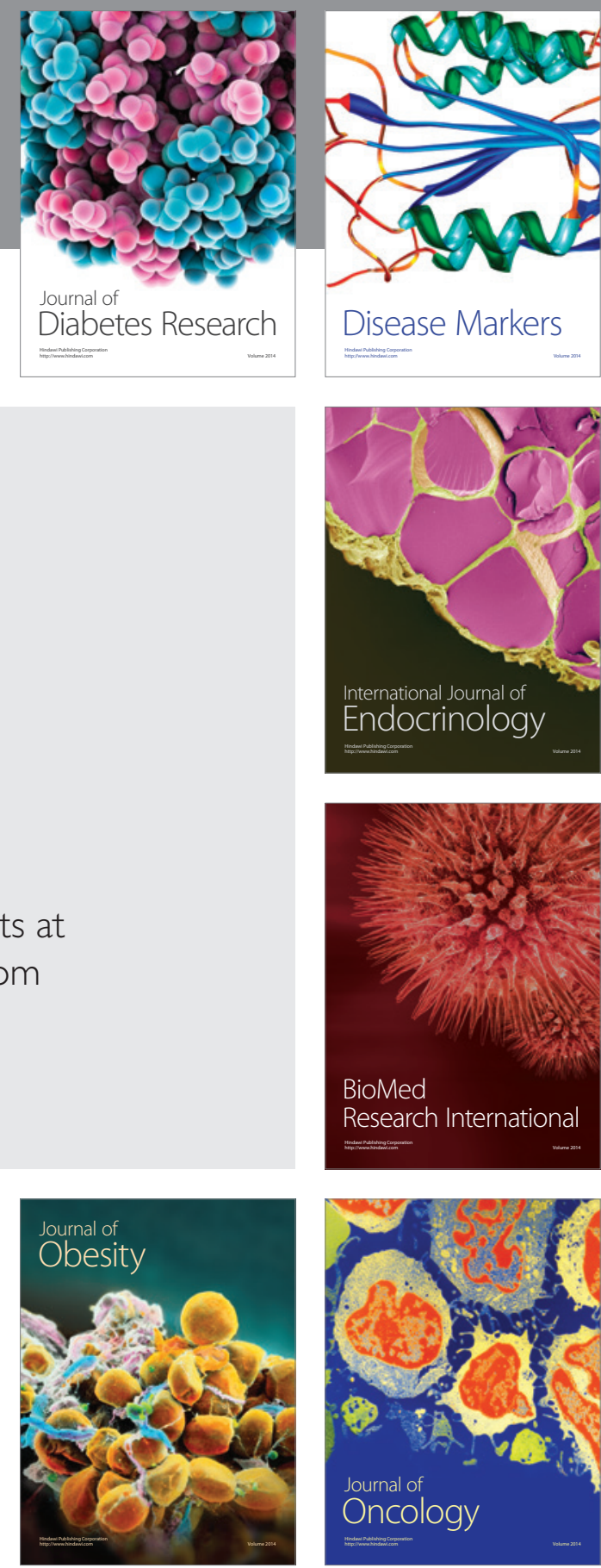

Disease Markers
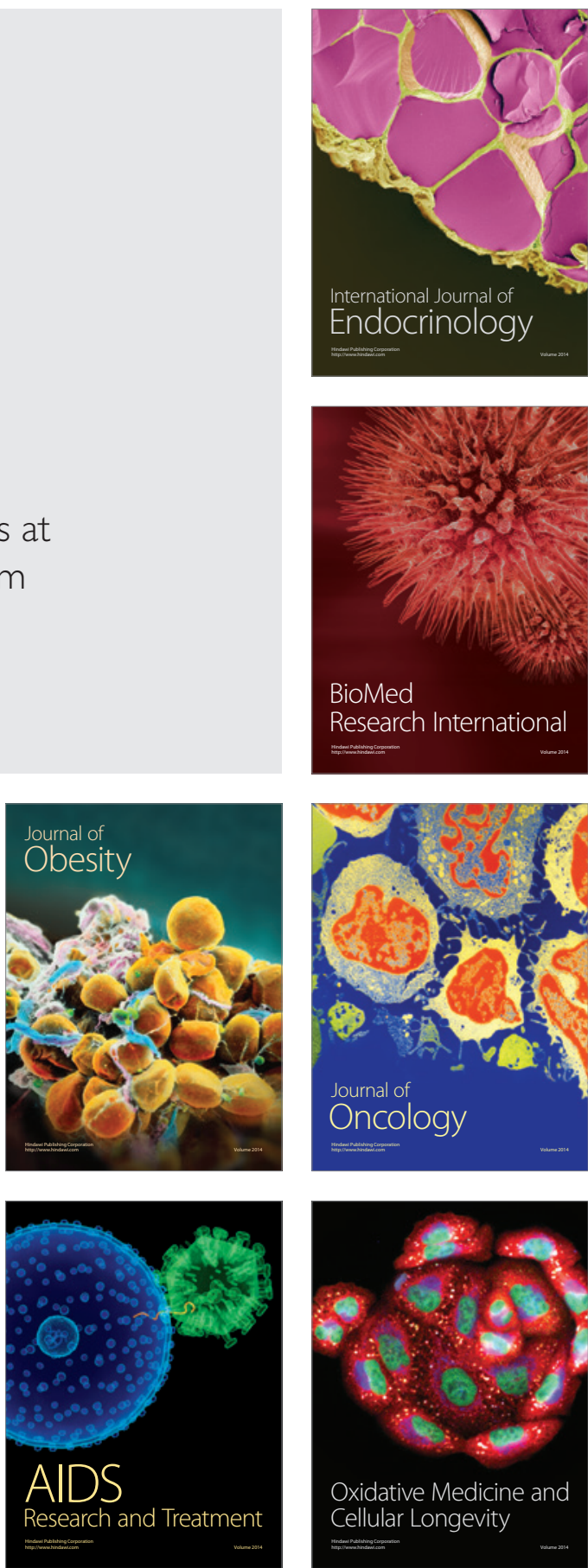